\title{
“A Journey to a Star"': Refletindo sobre o Processo de Construção de um Carmen Miranda como um Ícone Brasileiro/Latimo nos EUA
}

\author{
"A Journey to a Star:": reflecting about the contruction process of \\ Carmen Miranda as a Brazilian/Latino icon in the USA
}

Sônia Melo de Jesus Ruiz*

* Universidade do Estado do Rio de Janeiro, UERJ, Rio de Janeiro - RJ, 20550-900, e-mail: smjruiz@yahoo.com

\begin{abstract}
RESUMO: O artigo descreve a ascensão meteórica de Carmen Miranda como artista de sucesso nos EUA no final da década de 30 e na década 40, analisando não só as condições em que essa jornada para o estrelato se deu, mas seu impacto na construção de Miranda como um ícone brasileiro nos Estados Unidos. A partir das teorias de Francesco Alberoni (1962) e Richard Dyer (1998) sobre estrelato, Carmen Miranda é analisada como um texto em aberto, um fato social, e é estudada sob os aspectos de sua significação ideológica num período histórico que promoveu a conhecida "Política da Boa Vizinhança", na qual interessava aos EUA consumir a América Latina e sua cultura. Por meio da análise de diversos jornais de grande circulação nos EUA, percebe-se que a artista imigrante se integra ao modelo americano pós-colonial de consumo cultural latino-americano nas suas inúmeras apresentações artísticas no palco e fora dele, ditando moda e sendo referência de estilo. Mas, ao mesmo tempo que consume, Carmen é também consumida por este modelo, perdendo sua expressão nacional brasileira e vindo a ser entendida como uma figura híbrida e pan-étnica que anos mais tarde seria chamada de "Latina".
\end{abstract}

PALAVRAS-CHAVE: Carmen Miranda; imigrantes Latinas; consumo cultural.

ABSTRACT: The article describes the meteoric rise of Carmen Miranda as a successful artist at the end of 1930s and during the 40s, analyzing not only the conditions in which her journey to the stardom happened, but also its impact in the construction of Miranda as a Brazilian icon in the United States. Using the theories of Francesco Alberoni (1962) e Richard Dyer (1998) about stardom, Carmen Miranda is considered an open text, a social fact, and her multiple ideological meanings are studied bearing in mind the historical period events, when the well known "Good Neighbor Policy" was implemented, and made the USA very interested in consuming Latin America and its culture. Examining various newspapers of great circulation in the USA, it can be observed that the immigrant artist integrated herself very well in the post-colonial US American Latin American cultural consumerism model while performing on and off stage, dictating the latest fashion trends at the time and being a living life style reference. However, Miranda consumes but is also consumed by this model,

\footnotetext{
${ }^{1}$ Música de ROBIN, L e WARREN, H., A journey to a star foi interpretada por Carmen Miranda, Alice Faye, Sheila Ryan e outros atores no filme de BERKLEY, B., Entre a loura e a morena (1942).

Volume 18

Número 40
} 


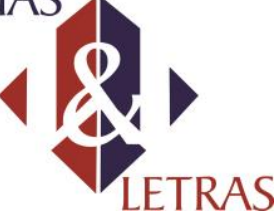

losing her national Brazilian identity and being understood as a hybrid and panethnical star that would be later called "Latina".

KEYWORDS: Carmen Miranda; Latina immigrants; cultural consumerism.

Maria do Carmo Miranda da Cunha nasceu em 9 de fevereiro de 1909, na cidade de Marco de Canaveses, Portugal. Veio morar no Rio de Janeiro ainda pequena, com apenas dez meses de idade, junto dos pais e da irmã Olinda, de dois anos. Começou a trabalhar com quatorze anos para ajudar nas despesas da família, após a morte de Olinda, causada pela tuberculose. Porém, seu sonho de ser uma cantora de sucesso só foi realizado em 1929, quando gravou sua primeira música pela Brunswick, "Não vá sim'bora”, do compositor Josué de Barros. Três anos mais tarde, estrearia seu primeiro filme, O carnaval cantado no Rio (1932), um média-metragem rodado pela Vital Ramos Castro Produtora. Nascia assim Carmen Miranda, que em 1933 receberia do radialista César Ladeira o carinhoso apelido de "pequena notável".

A trajetória de sucesso de Miranda foi singular e, em poucos anos, a artista conquistou papéis importantes em vários filmes, gravou diversas músicas, cantou em rádios, cassinos e teatros do Brasil, vindo a tornar-se uma celebridade nacional. Contudo, só em 4 de maio de 1939 as portas do estrelato internacional se abririam para ela. De "pequena notável", Carmen seria agora a "Brazilian bombshell".

Após um convite de Lee Shubert, famoso produtor da Broadway, Carmem imigrou para os Estados Unidos, contratada para participar do elenco do novo espetáculo As ruas de Paris (The streets of Paris). Shubert ouvira nossa famosa cantora no Cassino da Urca e se encantara por sua performance, no traje de baiana estilizada que imortalizaria a música de Dorival Caymmi, “O que é que a baiana tem?”, incluída no filme brasileiro Banana da terra (1939). Em sua despedida do Brasil, na rádio Mayrink Veiga, Carmen promete ir para Nova York divulgar a música brasileira, mas promete também voltar:

Meus queridos ouvintes. Venho dizer adeus a vocês. Não esse adeus que é uma separação, mas um adeus que é uma saudade. Sigo para Nova York onde vou apresentar a música da nossa terra. Lá, no meio daquela gente amiga, mostrarei a cadência alegre da música brasileira. Tenho, às vezes, receio da responsabilidade, mas na hora $\mathrm{H}$, quando eu abrir a boca e perguntar ao público - o que é que a baiana tem?, sinto que o calor da torcida dos meus amigos que me ouvem agora me dará para responder com aquele it que vocês sabem - Tem torço de seda, tem... Despeço-me, agora, por este microfone. Quando voltar, contarei muitas coisas bonitas... Adeus, meus bons amigos. Lembrem- 


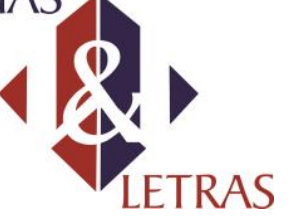

e-ISSN: 1981-4755

DOI: $10.5935 / 1981-4755.20170018$

se sempre de mim, que eu não os esquecerei nunca! (BARSANTE, 1994, p. 31)

Carmen Miranda não poderia prever a dimensão dos eventos que sucederiam ao seu número de baiana estilizada no Cassino da Urca naquela noite de 1939. Aquela produção brasileira ganharia outros significados nos Estados Unidos, e a imagem de Carmen alcançaria diferentes significações que fugiriam do script da indústria do entretenimento responsável por criá-la. A sociedade estadunidense consumiria Miranda em diversos níveis e descobriria que a baiana tinha muito mais do que torço de seda, balangandãs, sandálias enfeitadas e requebrado.

A artista foi notícia em muitos jornais e revistas de grande circulação nos EUA, como The New York Times, The Los Angeles Times, The Wall Street Journal e The Washington Post. Não faltaram resenhas sobre seus espetáculos e participações no teatro e no cinema. Esse processo de ascensão meteórica de Miranda nos Estados Unidos merece destaque, pois até os dias de hoje ainda não temos outro/a artista que tenha nos representado tanto no mercado e na mídia estadunidense como ela. Faz-se necessário, então, entender de que forma foi possível a Miranda alcançar a posição de estrela na terra do Tio Sam e como se deu essa jornada para o estrelato.

Richard Dyer (1998), em seu consagrado livro Stars, analisa o estrelato por meio da dialética dos elementos sociológicos e semióticos envolvidos nesse fenômeno. Ele caracteriza o estrelato como um fenômeno social e um aspecto da natureza industrial dos filmes que precisam ser entendidos, dentro de seus contextos e significados próprios (Cf. DYER, 1998, p.1). Como textos, em sentido lato, as estrelas são fatos sociais e, portanto, também precisam ser estudadas sob os aspectos de suas significações ideológicas. Nessa perspectiva, o autor destaca algumas condições, já descritas por Francesco Alberoni (1962), para que o estrelato seja possível: um estado legalizado [ $a$ state of laws], uma burocracia eficiente, um sistema social estruturado, uma sociedade de larga escala, desenvolvimento econômico acima da subsistência e mobilidade social (DYER, 1998, p.7) - elementos inquestionavelmente presentes na sociedade estadunidense do final dos anos 1930 e 1940, com a qual Carmem Miranda interagiu.

A década de 1930 nos EUA foi marcada pela tentativa de recuperação após o crash da bolsa de valores de Nova York. Em 1933, o então presidente eleito Franklin D. Roosevelt anunciava o New Deal, um pacote de reformas econômicas, políticas e sociais que tinha a missão de restaurar a prosperidade americana, resolvendo problemas como o desemprego de cerca de treze milhões de estadunidenses, a falência de bancos e 


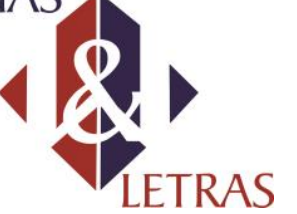

e-ISSN: 1981-4755

DOI: $10.5935 / 1981-4755.20170018$

empresas, além do colapso da economia agrícola. Era uma época de reformas econômicas e sociais já conhecidas dos europeus, mas novas nos Estados Unidos. Agora haveria maior intervenção do Estado na economia, com o abandono do chamado capitalismo laissez-faire praticado pelos antecessores de Roosevelt. O mundo também havia sofrido o impacto da Grande Depressão americana. Ao mesmo tempo, regimes totalitários no Japão, na Alemanha e na Itália se expandiam, fomentando uma nova guerra mundial que estava prestes a eclodir, e novas ditaduras surgiam na América Latina, como o Estado Novo de Vargas no Brasil.

Tantas transformações também afetariam a produção artística dos EUA, como demonstra Michael Denning (1998) no seu livro The cultural front. O autor analisa profundamente a década de 1930 nos EUA como a época do surgimento de uma nova cultura enraizada em ideais socialistas que impactaram a sociedade daquele país de maneira irreversível. Para tanto, Denning (Cf. 1998, p. 4) fornece-nos informações históricas que serviram de pano de fundo para a Frente Popular, um movimento social antifascista, do segmento de esquerda do New Deal. O autor apresenta a história da Frente Popular e as maneiras pelas quais ela ajudou a produzir uma cultura trabalhista em meio ao liberalismo do New Deal, ao populismo, à cultura social e industrial democrática e ao sindicalismo industrial (Cf. DENNING, 1998, p. xvii). A grande sociedade estadunidense contava agora com um Estado mais eficientemente burocrático, com leis e estruturas recém-criadas pelo governo e uma economia que crescia para além da subsistência, além de movimentos sociais que lutavam por um sistema mais justo, pela qualidade de vida dos seus cidadãos e pela possibilidade de ascensão social - elementos condicionais do estrelato, conforme vimos anteriormente.

Embora as condições para o estrelato descritas por Dyer (Cf. 1998, p. 9) contextualizem o fenômeno, não são capazes de explicar por que as estrelas surgem. Para o autor, é preciso, então, entender que as estrelas são o resultado tanto da demanda pública quanto da iniciativa de produtores (Cf. DYER, 1998, p.10-17). No caso especial de Carmen Miranda, precisamos enfatizar a maior demanda de artistas latinoamericanos nos EUA durante a década de 1930 como resultado da implementação da política da boa vizinhança adotada pelo governo do presidente Roosevelt, que visava a promover uma maior difusão das culturas latino-americanas e, consequentemente, a aproximar seus respectivos mercados. 


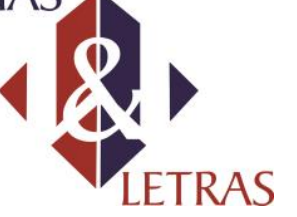

e-ISSN: 1981-4755

DOI: $10.5935 / 1981-4755.20170018$

A política de integração entre as Américas, iniciada em 1933 e conhecida como política da boa vizinhança, traria um impacto inimaginável ao Brasil e a todas as Américas.

A política da boa vizinhança de Roosevelt representou a criação de parcerias jamais vistas entre os países sul-americanos e os EUA, por meio do Office of Commercial and Cultural Relations between the American Republics, que, em 1941, um ano após sua criação, passou a se chamar Office of the Coordinator of Inter-American Affairs, o conhecido Bureau Interamericano. Como destaca Ana Maria Mauad (2001, p. 135), o objetivo desse órgão, sob chefia de Nelson Rockefeller, era o de "garantir a posição estratégica dos aliados do Cone Sul, a partir do avanço das forças do eixo Pacífico" e assim consolidar a política externa americana para a América Latina. Dessa política externa, destacam-se, desde o século XIX, "sucessivas posturas intervencionistas da Doutrina Monroe - América para os americanos -, seguida pelo Big Stick, até chegar ao pan-americanismo da Segunda Guerra Mundial, inaugurado por F. Delano Roosevelt a partir de 1933” (MAUAD, 2001, p. 135, grifo da autora). Como afirma Mauad (2005, p. 45),

havia o declarado interesse, por parte do Departamento de Estado dos EUA, em consolidar a presença norte-americana na América Latina através de acordos comerciais, planos de cooperação internacional e, por fim, de alianças políticas que garantissem a hegemonia dos Estados Unidos na região. (Mauad, 2005, p. 45)

Um artigo do The New York Times de agosto de 1941 declara sobre o primeiro ano de Nelson A. Rockefeller como coordenador do Bureau: “[...]ontem [Nelson A. Rockefeller] reportou sucesso nos passos dados para conter a influência nazista na América Latina e no interesse da defesa nacional” (LATIN..., 1941, p.11). O mesmo artigo ainda revela que o orçamento inicial de três milhões de dólares reservado ao Bureau teria como meta a criação de um banco interamericano, publicações turísticas, etc.

Sendo assim, as indústrias americanas foram convocadas a intensificarem seus investimentos na América Latina, como destaca uma reportagem do The New York Times sobre um almoço da Junta de Comércio de Nova York, em 20 de fevereiro de 1942, do qual participaram mais de 500 pessoas, incluindo vários diplomatas latinoamericanos. No artigo, o Sr. Rovensky, chefe financeiro do Bureau Internacional, diz aos empresários americanos presentes: "Torne-se um discípulo e, até o ponto em que sua influência alcance, tome iniciativa, fale sobre isso e promova as relações inter- 


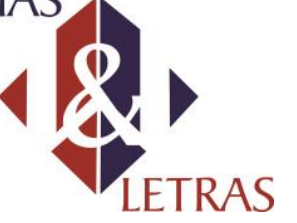

americanas para que, quando a guerra acabar, as novas Américas estabeleçam o padrão e provem que o progresso só vem com a decência e paz.” (ASK..., 1942, p.27).

Mauad (2001, p. 136) destaca que a atuação do Bureau Internacional no Brasil se manifestou em três áreas - informação, saúde e alimentação - e ainda explica: "Estes três setores tinham funções definidas de penetração e convencimento ideológico, através do controle dos meios de comunicação, investimento massivo em publicidade e fomento de uma estrutura assistencialista para a saúde e educação [...]".

Ela expõe também que "grandes companhias americanas apoiavam o Bureau, como a General Electric, a General Motors, a Light and Power Co. e The National City Bank of New York, entre outras.” (MAUAD, 2001, p. 136). A publicidade ostensiva do American way of life seria a maneira pela qual os empresários americanos garantiriam um mercado de consumo contínuo e, consequentemente, o escoamento de sua produção - que fora intensificada no pós-guerra. Nesse contexto, não poderia faltar o investimento do Bureau em produções culturais, como, por exemplo, a montagem do filme Serenata tropical (Down Argentine way), de 1940.

A visita do produtor da Broadway Lee Shubert ao Rio de Janeiro fazia, portanto, parte das ações promovidas pela mídia e indústria de entretenimento dos EUA, uma das responsáveis por garantir o sucesso esperado com a implantação dessa nova política externa, que incluía o Brasil nos países latinos componentes da agenda estadunidense. Ana Rita Mendonça (1999, p. 19), em seu livro, Carmen Miranda foi a Washington, destaca:

Na Urca, Shubert gostou do que viu. Desde que o Presidente Franklin Roosevelt anunciou a política de boa vizinhança proliferaram talentos latinos nos Estados Unidos. Shubert tinha vindo visitar a América do Sul, não o Brasil. Para o empresário, aquela porção do continente estava ali, bem diante dele, cantando, dançando e rindo dentro de uma baiana. "The South American Way", ainda cantaria Carmen. (Mendonça, 1999, p. 19)

Estavam, então, abertos os canais necessários para a maior integração das repúblicas americanas, o que ia ao encontro da política de Vargas, desejoso de promover o Brasil no exterior. Mendonça (1999, p. 56) declara:

Esforçava-se a propaganda estado-novista para divulgar o nome do Brasil no exterior, fosse veiculando uma Hora do Brasil em Buenos Aires ou mantendo um bureau de informações em Nova York. No caso de Carmen Miranda, o próprio presidente teria participado do 


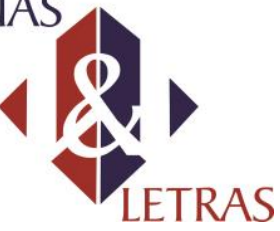

e-ISSN: $1981-4755$

DOI: $10.5935 / 1981-4755.20170018$

primeiro passo internacional de nossa estrela maior. (Mendonça, 1999, p. 56)

Mendonça (1999) se refere ao fato de ter sido o governo brasileiro que financiou as passagens do Bando da Lua, grupo musical que acompanhou Carmen Miranda em Nova York, uma vez que o convite do produtor Lee Shubert para uma temporada nos EUA se restringia a Carmen.

Carmem Miranda serviu como representante do Brasil numa época em que importava aos Estados Unidos desenvolverem uma política de boa vizinhança, como afirmaria Strauss (1941, p. X5), colunista do The New York Times: "Desde que Carmen Miranda nos mostrou o que a política da boa vizinhança realmente significa, este departamento observa com novo interesse quaisquer outros esforços para criar solidariedade entre nossas gloriosas repúblicas do Oeste”.

E, ao Brasil, interessava deixar-se representar na figura de sua "pequena notável”, como observa Mendonça (1999, p. 12-13):

A máquina de propaganda do Estado Novo sonhou fazer de Carmen
Miranda seu cartão de visita no exterior. Surgiu a possibilidade de
circular numa indústria cultural plenamente estabelecida, capaz de
formar braços externos, aqui despejando filmes e canções a rodo.
Estrela maior, ao partir para esse universo de possibilidades, Carmen
foi depositária dos sonhos de uma nação [...]. Foi a musa da política
de boa vizinhança. Mas não teria como escapar dos resistentes
estereótipos norte-americanos para a América Latina. (Mendonça,
1999, p. 12-13)

A ida de Carmen Miranda para os "Esteites" se insere, portanto, em um plano muito mais abrangente, no qual vários interesses econômicos, e principalmente políticos, estavam em jogo. Nesse contexto, seu papel era o de representar seu país, o Brasil, e difundir nossa cultura, como ela mesma percebe:

Coube-me a grande oportunidade e a grande honra de ser a intérprete das coisas brasileiras. [...] Vou botar tempero brasileiro no gosto e no goto daquela boa gente... Nos meus números não vai faltar nada: canela, pimenta, dendê, cominho... Vou levando vatapá, caruru, munguzá, balangandãs, acarajé... [...] Eu quero que o americano conheça o samba, compreenda que não é rumba. Não vou esquecer a minha terra. Nem me americanizar. Vou levar um pouco do Brasil (A CARIOCA, apud. MENDONÇA, 1999, p. 57).

Carmen Miranda tinha tudo o que uma baiana deveria ter - só ainda não sabia, ou não demonstrava saber, que, para a Broadway, suas marcas de brasilidade pouco importariam. Em um artigo do The New York Times, uma resenha sobre As ruas de Volume 18

Número 40 


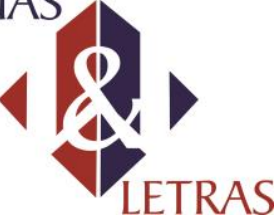

Paris assinada por Brooks Atkinson (C.f. 1939, p. 29), nota-se que, apesar de se saber que Carmen era do Brasil, não se percebia que ela cantava em português, e dizia-se que era em espanhol. Em seu primeiro filme, Serenata tropical, Carmen interpreta uma brasileira que canta em português. O mais intrigante é uma matéria publicada no The Washington Post em 1940: Franklin Arthur (1940, p. 18) comenta a crescente crítica do filme por parte dos sul-americanos e afirma que Serenata tropical é mais um exemplo da ignorância dos estadunidenses sobre a América do Sul, pois, entre outros erros, “[...] Carmen Miranda, uma brasileira, é representada como uma argentina que canta suas canções em português". Ele destaca ainda um comentário feito por um correspondente argentino sobre o filme: "Este é apenas um em uma longa série de exemplos que demonstram a colossal e chocante ignorância sobre a América do Sul e as pessoas ao sul do rio Grande.” (ARTHUR, 1940, p. 18). Porém, Arthur não percebe que, no filme, há uma cena em que a entrada da casa de espetáculos El Tigre, onde Carmen Miranda se apresenta, mostra seu letreiro luminoso com a seguinte inscrição: "Brazilian sensation" - sensação brasileira, e não argentina, como afirmara. O colunista que escreveu um artigo para enfatizar a má recepção de Serenata tropical por parte dos sul-americanos e criticar a indústria cinematográfica, por apresentar informações erradas, também se equivoca. $^{2}$

Sendo assim, já estava traçado todo o plano de criação de um imaginário latinoamericano nos EUA, articulado pela indústria do entretenimento estadunidense, na busca de um novo mercado de consumo na América Latina. E foi justamente por se inserir nesse projeto que, nos anos 40, em uma de suas últimas viagens para o Brasil, Carmen Miranda se apresentou no Cassino da Urca para uma platéia ansiosa em ver sua “pequena notável” agora como estrela internacional - platéia que, nessa ocasião, a vaiou, tachando-a de "americanizada". Mas, na verdade, Carmen voltara "latinizada", por isso a platéia não reconhecera nela o ícone de brasilidade de outrora.

Ao entender as estrelas como imagens em textos da mídia, Dyer (1998, p. 1016) destaca que as estrelas, como fenômeno da produção, são comumente consideradas

\footnotetext{
${ }^{2}$ Mesmo depois de o filme sofrer várias alterações para poder ser apresentado na Argentina, a versão que temos hoje em dia de Serenata tropical ainda é repleta de exemplos de como as coisas não funcionam na América do Sul. Podemos destacar: o atraso de três horas no aeroporto enfrentado pelos personagens, a secretária confusa da embaixada, que não entende que a personagem americana Glenda Crawford, interpretada por Betty Grable, quer ingressos para o concerto, o motorista Anastásio que vive dormindo em serviço, e Tito Acuña, um guia turístico espertalhão que ganha dinheiro fazendo um tour pelas casas de show de Buenos Aires com Glenda.

${ }^{3}$ Ser latinizada significa ser homogeneizada etnicamente, entendida como pertencente a uma cultura exótica, originada na América Central e do Sul, mas praticada no território dos EUA, altamente estereotipada e agora visível através do filtro da política da boa vizinhança.
}

Volume 18

Número 40 


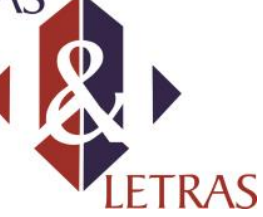

fruto da economia, manipulação do mercado e da moda, bem como da mágica e do talento pessoais, ou mesmo como resultado natural do meio cinematográfico.

Em termos econômicos, as estrelas são consideradas o capital dos produtores, ao mesmo tempo investimento e despesa. Ao analisarmos a artista Carmen Miranda, dentro dessa ótica, é fácil percebermos que ela representou um investimento muito lucrativo para o produtor Shubert. As ruas de Paris foi o primeiro de muitos musicais de sucesso com a artista. Muitas foram as críticas positivas sobre o espetáculo após sua estréia, como a resenha de Brooks Atkinson (1939, p. 29) e outras em The New York Times e em The Wall Street Journal.

Para a própria Miranda, a parceria com Shubert também seria muito lucrativa. Segundo Cássio Emmanuel Barsante (1994, p. 30) em Carmen Miranda, uma biografia ilustrada da "pequena notável", o contrato com o produtor da Broadway lhe dava o direito a um salário semanal inicial de 400 dólares e uma porcentagem de cinqüenta por cento quando participasse de outros trabalhos, um bom salário para uma estreante. Em 22 de junho de 1939, Miranda alugava um apartamento duplex no Central Park West, número 25, um endereço em uma área nobre da Big Apple, com uma vizinhança repleta de famosos (Cf. RENTING..., 1939, p. 40). Seu sucesso em As ruas de Paris lhe garantiu participações em outros musicais do produtor, além de lhe proporcionar ampla exposição ${ }^{4}$. Carmen foi garota-propaganda de anúncios de cerveja, inspiração para a criação de bijuterias da Leo and Glass Co., além de blusas, suéteres, chapéus e turbantes da marca Hi-Yi The South American Way, vendidos em lojas como a Macy's e Saks Fifth Avenue (Cf. BARSANTE, 1994, p. 15-16) - uma manipulação clara da indústria do entretenimento, que produziu não só a bombshell Carmen Miranda, mas vendeu sua imagem para empresas de bens de consumo, associando-a a uma latinidade que incorporava elementos de exuberância, glamour e sensualidade.

Shubert foi crucial nesse processo, pois tinha uma assessoria de imprensa que investia muito na divulgação de seus contratados. O produtor se preocupou até em "retocar" a biografia de Miranda: deixou-a cinco anos mais jovem e tornou-a filha de atacadista de queijos e frutas - o que seria mais atraente do que ser filha de um barbeiro - sem, entretanto, fazer com que perdesse um caráter de singeleza e simplicidade (Cf. MENDONÇA, 1994, p. 74). A mensagem indireta estaria, então, lançada: estrelas são

\footnotetext{
${ }^{4}$ Além da Broadway ser visitada por pessoas de todas as partes dos EUA e até mesmo de fora do país, Carmen Miranda estreara no musical As ruas de Paris por ocasião da Feira Mundial, evento que contava com a participação de figuras nacionais e internacionais importantes que também circulavam na cidade e nos locais de entretenimento de Nova York.
}

Volume 18

Número 40 


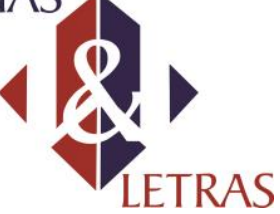

e-ISSN: 1981-4755

DOI: $10.5935 / 1981-4755.20170018$

gente como a gente, possíveis de serem imitadas; estrelas alcançam sucesso por meio de suas qualidades e talentos individuais (embaladas, é claro, por um sistema igualitário e cheio de boas oportunidades); e o American Dream não é um mito. Afinal de contas, se as estrelas são imagens manipuladas, produtos da indústria do entretenimento que inspiram sonhos de consumo, como sugere Dyer (1998), devem estar sempre associadas a uma personalidade e um estilo de vida invejáveis, para que, assim, sejam capazes de manter-se no estrelato. Consequentemente, o estrelato, de maneira geral, é uma versão do sonho americano organizado em torno do consumo, sucesso e normalidade [ordinariness] (Cf. DYER, 1998, p. 35).

No mesmo ano de sua estréia, 1939, Carmen Miranda iniciava sua carreira cinematográfica pela produtora 20th Century Fox. Em pouco tempo, a Brazilian bombshell, que já havia participado de seis filmes no Brasil ${ }^{5}$, estreava no filme Serenata tropical, conforme vemos no anúncio publicado em The Washington Post.

Junto com o Bando da Lua, Miranda apresentou três canções no longa-metragem em technicolor: "South American way", "Mamãe eu quero" e "Bambu, bambu" - sendo que as duas primeiras estão entre as mais conhecidas músicas de seu repertório nos Estados Unidos. Acompanhada de um elenco de peso (Betty Grable, Charlotte Greenwood e Don Ameche), Miranda atuou como ela mesma e, mais uma vez, foi aclamada pela crítica:

Em 1941, Miranda emplacou outros dois sucessos de bilheteria pela 20th Century Fox, Uma noite no Rio (That night in Rio) e Aconteceu em Havana (Week-end in Havana).

No primeiro filme, ambientado no Rio de Janeiro, Miranda foi acompanhada pelo Bando da Lua, cantando e encantando com "Chica chica boom chic", "Cae cae", "I like you very much - I, yi, yi, yi, yi”. Já no segundo filme, Miranda atuou como Rosita Rivas, uma cantora que é a atração principal do Cassino Madrileño, em Havana. Ela foi acompanhada, novamente, por sua banda e apresentou quatro músicas: "A week-end in Havana"; "When I love, I love"; "Rebola bola" e "The nango".

Porém, seus primeiros sucessos hollywoodianos trouxeram atritos com os Shubert. Louella O. Parsons (1941, p. 11), colunista do The Washington Post, em 18 de

\footnotetext{
${ }^{5} 1932$ - O carnaval cantado no Rio - Cinédia, 1933 - A voz do carnaval - Cinédia, 1935 - Alô, alô Brasil! - Waldow - Cinédia, 1935 - Estudantes - Waldow - Cinédia, 1936 - Alô, alô carnaval- Waldow - Cinédia e 1939 - Banana da terra - Sonofilmes.
} 


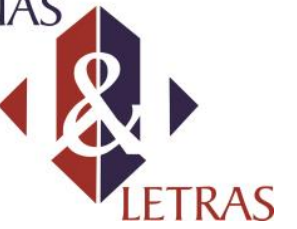

e-ISSN: 1981-4755

DOI: $10.5935 / 1981-4755.20170018$

fevereiro de 1941, afirmou que Carmen Miranda exigia ajustes salariais no seu contrato, agora que era estrela também em Hollywood.

Um mês depois, em 24 de março de 1941, convidada por Sidney Grauman, Miranda imortalizou sua presença no estrelato estadunidense como o único ícone brasileiro a deixar as impressões de suas mãos e sandálias plataforma na Calçada da Fama do Teatro Chinês em Hollywood ${ }^{6}$, fato que dificultou ainda mais as negociações salariais pendentes.

Com isso, as divergências entre Carmen Miranda e os Shubert se intensificaram, o que a levou a desfazer seu contrato, após o pagamento de 60 mil dólares, em 23 de julho de 1942 (Cf. BARSANTE, 1994, p. 31). A partir daí, George Frank, agente do ator Don Ameche, colega de filmagens de Uma noite no Rio e Serenata tropical, passou a ser o novo manager da artista, cobrando apenas dez por cento de seus lucros, quantia bem inferior aos cinqüenta por cento cobrados por Lee Shubert (Cf. BARSANTE, 1994, p. 94).

Miranda ainda atuaria em mais 11 filmes nos EUA: Minha secretária brasileira (Springtime in the rockies), 1942, Entre a loura e a morena (The gang's all here), 1943, Quatro moças num jipe (Four jills in a jeep), 1944, Serenata boêmia (Greenwich village), 1944, Alegria, Rapazes! (Something for the boys), 1944, Sonhos de estrela (Doll face), 1945, Se eu fosse feliz (If I'm lucky), 1946, Copacabana, 1947, O príncipe encantado (A date with Judy), 1948, Romance carioca (Nancy goes to Rio) 1950 e Morrendo de medo (Scared stiff), 1953.

Carmen Miranda ganhara, assim, ao longo dos anos, notoriedade incontestável e presença garantida em colunas sociais, revistas e cadernos de moda de jornais de grande circulação dos EUA. Seus balangandãs multicoloridos e suas sandálias plataforma eram sempre comentados. Lydia Lane (1953, p. C9), colunista do jornal Los Angeles Times, já dizia sobre Carmen:

A contribuição do Brasil a Hollywood, Carmen Miranda, teve maior impacto em nosso jeito de viver do que percebemos. Ela introduziu a

\footnotetext{
${ }^{6}$ Após deixar suas marcas na calçada da fama, Carmen dá uma entrevista e deixa o seguinte recado para seus fãs brasileiros: "Meus queridos amigos de todo o Brasil. Aqui estou falando a vocês do Chinese teatro de Hollywood, onde acabo de botar minhas mãozinhas e meus pezinhos no cimento. Podem crer que foi um dos momentos mais felizes da minha vida. E nesse momento eu juro que pensei em vocês. Uma grande saudades e meu beijo melhor." (CÂMARA MUNICIPAL DE MARCO DE CANAVESES. Biografia de Carmen Miranda. Disponível em:< https://www.cm-marco-canaveses.pt/index.php?info $=$ YTo0OntzOjQ6Im1lbnUiO3M6M zoi $\quad$ Y2Ft IjtzOjM6Im1pZCI7YTo1OntpOjA7czoyOiIyNyI7aToxO3M6MjoiMjkiO2k6MjtzOjI6IjQwIjtpOjM7czo $\mathrm{y}$

OiI4MiI7aTo0O3M6MjoiODMiO31zOjM6ImNpZCI7czoyOiI4MyI7czoxMzoidmVyc2FvX3RhYmVsY

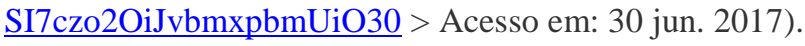

Volume 18

Número 40
} 


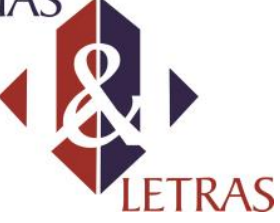

"barriga de fora", seus colares grandes e pulseiras foram copiados por joalheiros e nós temos que agradecer a Carmen pelo salto alto confortável conhecido como plataforma. (LANE,1953, p. C9) ${ }^{7}$

Miranda, porém, também consumia o American dream. Depois de clarear seus cabelos, disse, em entrevista a Lydia Lane (1953, p. C9), que tornar-se loura a fez mais popular entre os homens: "Meu cabelo louro trouxe sorte com os homens - me trouxe o meu marido. Ele ama louras”. Carmen referia-se a David Alfred Sebastian, com quem se casara em 17 de março de 1947. Juntos, moraram em uma mansão no bairro das estrelas, Beverly Hills. Miranda era até entrevistada sobre sua dieta, que poderia ser enviada pelos correios aos fãs que escrevessem à jornalista Lydia Lane. A estrela se transformara em modelo de consumo da sociedade estadunidense da época. Seu estilo de vida, suas roupas e acessórios eram imitados, e seu corpo, desejado.

Contudo, o trabalho era uma constante na vida da artista. Como Miranda mesmo afirma:

Eu trabalho muito duro. Algumas vezes meu empresário me agenda por 12 semanas - algumas vezes eles [os shows] são em cidades diferentes a cada dia. Eu chego morta. Eu sei que preciso fazer uma coisa, relaxar. Eu não vejo amigos. Eu não vou para nenhuma festa. (LANE, 1953, p. C9) ${ }^{8}$

Segundo sua irmã, Aurora Miranda, Carmen quase não comia e dormia muito pouco. Fazia uso de tranquilizantes para poder dormir e dar conta de uma agenda lotada, em um ritmo insuportável de trabalho (Cf. BARSANTE, 1994, p. 162-164). Em 1953, não respeitou as recomendações médicas de tirar férias por três meses; no ano seguinte, teve um colapso nervoso e foi até submetida a tratamentos à base de choques elétricos. Fez, então sua última viagem ao Brasil, acompanhada de Aurora, para descansar.

O sucesso da nossa "pequena notável” seria marcado por um fim trágico. Em 5 de agosto de 1955, acometida de um infarto fulminante, morreu em sua mansão aos 46 anos de idade. Ela foi encontrada caída no chão de seu quarto, por seu marido. O corpo foi trasladado para o Rio, onde foi enterrado no Cemitério São João Batista. A estrela fazia sua jornada para o céu.

De estrela, Carmen vira lenda, mito, referência e ganha significados diversos, em diversos contextos e em diferentes épocas. Carmen é imitada, recriada,

\footnotetext{
${ }^{7}$ Brazil's contribution to Hollywood, Carmen Miranda, has had more of an impact upon our way of life than is realized. She introduced midriffs, her bulky necklaces and bracelets were copied by jewelers and we have Carmen to thank for the comfortable heel known as a wedge.

8 "I work very hard. Sometimes my agent books me for 12 weeks - sometimes they are different cities every night. I come home dead. I know I must do one thing, relax. I see no friends. I go to no parties.” (LANE, 1953, p. C9)
}

Volume 18

Número 40 


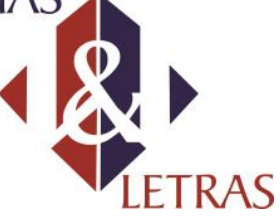

e-ISSN: 1981-4755

DOI: $10.5935 / 1981-4755.20170018$

ressignificada, parodiada, admirada e evocada. Ela se transforma em sinônimo do exagero, da sensualidade, da euforia, comumente associados ao estereótipo da latinidade, mesmo antes da formação de um mercado Latino nos Estados Unidos. Como esclarece Arlene Dávila (2001, p. 3-4), ao analisar esse mercado em seu livro Latinos Inc., antes de se criar um mercado consumidor Latino, é necessário "promover idéias generalizadas sobre "hispânicos", a fim de "moldar e projetar imagens dos e para os Latinos". E, nesse contexto, nossa espetacular artista estabeleceu-se no mercado estadunidense, servindo a esse propósito num momento histórico propício para a criação de uma pan-etnia Latina nos anos 1940.

\section{REFERÊNCIAS}

ALBERONI, Francesco. Powerless elite: theory and sociological research on the phenomenon of stars. Trad. Denis McQuail. In: REDMOND, Sean; HOLMES, Dr Su. Stardom and celebrity: a reader. (Ed.). Londres: Sage, 2007.Tradução de: L'Elite irresponsible: théorie et recherché sociologique sur 'le divismo', 1962.

ARTHUR, Franklin. Movies strive so boost trade in So. America. ProQuest historical newspapers The Washington Post. Washington, 17 nov. 1940, p. I8.

ASK business man to aid Latin policy. ProQuest historical newspapers The New York Times. Nova York, 20 fev.1942, p. 27.

ATKINSON, Brooks. The 'streets of Paris' moves to Broadway - Paul Robeson in 'The emperor Jones'. ProQuest historical newspapers The New York Times. Nova York, 20 jun.1939, p. 29.

CÂMARA MUNICIPAL DE MARCO DE CANAVESES. Biografia de Carmen Miranda. Disponível em:< https://www.cm-marco-canaveses.pt/index.php?info =YTo0OntzOjQ6Im11 bnUiO3M6M zoi Y2Ft IjtzOjM6Im1pZCI7YTo1OntpOjA7c zoyOiIyNyI7aToxO3M6M OiI4MiI7aTo0O3M6MjoiODMi joiMjkiO2k6MjtzOjI6IjQwIjtpOjM7czoy O31zOjM6Im NpZCI7czoyOiI4MyI7czoxMzoidmVyc2FvX3RhYmVsYSI7czo2OiJvbmxpbmUiO30 $>$ Acesso em: 30 jun. 2017).

BARSANTE, Cássio Emmanuel. Carmen Miranda. $2^{a}$ ed. Rio de Janeiro: Elfos, 1994. DÁVILA, Arlene. Latinos Inc.: the marketing and making of a people. Berkeley: University of California Press, 2001.

DENNING, Michael. The cultural front: the laboring of American culture in the twentieth century. Nova York: Verso, 1998.

DYER, R. Stars. London: British Film Institute, 1998.

LANE, Lidia. Carmen tells how she loses weight. ProQuest historical newspapers Los Angeles Times. Los Angeles, 1953, p. C9.

LATIN America unit achieving its goal. ProQuest historical newspapers The New York Times. Nova York, 11 ago. 1941, p.11.

MENDONÇA, Ana. Rita. Carmem Miranda foi à Washinghton. São Paulo: Record, 1999.

MAUAD, Ana Maria. A América é aqui: um estudo sobre a influência cultural norteamericana no cotidiano brasileiro (1930-1960). In: TORRES, Sonia. (Org.) Raízes e 


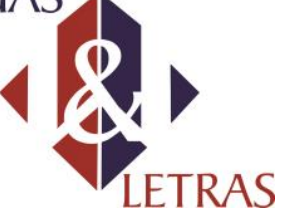

e-ISSN: 1981-4755

DOI: $10.5935 / 1981-4755.20170018$

rumos: perspectivas interdisciplinares em estudos americanos. Rio de Janeiro: 7Letras, 2001, p. 134-146.

. Genevieve Naylor, fotógrafa: impressões de viagem (Brasil, 1941-1942).

Revista brasileira de história. São Paulo: [s.n.], n. 49, v. 25, p. 43-75, 2005.

PARSONS, Louella O. Close-ups and long-shots of the motion picture scene. ProQuest historical newspapers The Washington Post. Washington, 29 set. 1939, p. 26.

Close-ups and long-shots of the motion picture scene. ProQuest historical newspapers The Washington Post. Washington, 18 fev. 1941, p. 11.

RENTING of suites holds active pace. ProQuest historical newspapers The New York Times. Nova York: 23 jun. 1939, p. 40.

ROBIN, L; WARREN, H. A journey to a star. Intérpretes: Carmen Miranda, Alice Faye, Sheila Ryan e outros. In: BERKLEY, B. Entre a loura e a morena, Hollywood: Twentieth Century Fox, 1942. Colorido.

Data de recebimento: 30/06/2017

Data de aprovação: 31/08/2017 